\title{
Nanoleakage in indirect composite restorations using different combinations of resin coating technique
}

\author{
Alberth David Correa Medina ${ }^{1}$, Andréia Bolzan de Paula ${ }^{2}$, Fabiana Scarparo Naufel ${ }^{3}$, Regina Maria Puppin-rontani ${ }^{4}$, \\ Lourenço Correr-Sobrinho ${ }^{2}$ and Mário Alexandre Coelho Sinhoreti ${ }^{2^{*}}$
}

\author{
* Correspondence: sinhoret@fop. \\ unicamp.br \\ 2Department of Restorative \\ Dentistry, Dental Materials Division, \\ Piracicaba Dental School, State \\ University of Campinas-UNICAMP, \\ Piracicaba, SP, Brazil \\ Full list of author information is \\ available at the end of the article
}

\begin{abstract}
The aim of this study was to evaluate the nanoleakage patterns in indirect composite restorations bonding to dentin using different combinations of Resin Coating, after thermal and load cycling. Twenty five extracted third molars were used in the study; two box-like Class II cavities were prepared in each tooth (mesial and distal surface). The 50 cavities were distributed in 5 groups according to the RC materials combinations: G1: Etch-rinse 2 steps/Hydrophobic monomer; G2: Etch-rinse 2steps/Flow composite-resin, G3: Self-etch 1step, G4: Self-etch1step/Flowable composite resin liner, G5: Self-etch 2step/Flowable composite-resin liner. The cavities were molded with a vinyl polysiloxane impression material and the molds were poured with stone plaster. The fillings were confectioned using the Sinfony composite system (3 M/ESPE) and cemented with resin luting cement (Rely $X$ ARC). After 24 hours, the teeth were submitted to thermocycling $\left(2000\right.$ cycles, $5^{\circ}$ to $55^{\circ} \mathrm{C}$ ) and load cycling $(250,000$ cycles, $30 \mathrm{~N}$ ). Past 24 hours, the restored teeth were sectioned into serial slabs and immersed in $50 \%$ ammoniacal silver nitrate for $24 \mathrm{~h}$, exposed to photo-developing solution for $8 \mathrm{~h}$, carbon coated and observed in SEM using backscattered electron mode. Diverse nanoleakage patterns were observed for the different RC combinations. Silver accumulation were observed in the entire thickness of the hybrid layer in G1 and G2 groups, while in the "all in one" self-etch groups (G3 and G4) silver accumulations similar to "water trees" within the adhesive layer were observed. In G5 group, less nanoleakage than other groups was observed and it was limited to the hybrid layer. The group G5 presented a superior behavior and revealed less nanoleakage compared to the other groups.
\end{abstract}

Keywords: Nanoleakage; Resin coating; Adhesives; I restorations

\section{Background}

One of the best alternatives for restoring extensive cavities is the indirect composite restoration; however, this kind of restoration demands a more invasive cavity preparation and may lead to a post-operative sensitivity [1].

The Resin Coating Technique (RCT) has been proposed as an attempting to avoid this hypersensitivity [2]. This technique consists in the hybridization of the exposed dentin followed by the application of a hydrophobic monomer or a low viscosity resin immediately after cavity preparation and prior to taking the impression [3]. The

\section{Springer}

(c) 2014 Medina et al.; licensee Springer. This is an open access article distributed under the terms of the Creative Commons Attribution License (http://creativecommons.org/licenses/by/2.0), which permits unrestricted use, distribution, and reproduction in any medium, provided the original work is properly cited. 
immediate dentin sealing technique offers several advantages. First, resin adhesion can be improved by bonding to freshly cut dentin and by polymerization of the resin adhesive without any stresses related to curing of the resin cement that will overlie it. Second, the adhesive provides a seal that reduces bacterial contamination, tooth sensitivity, and the need for anesthesia at the delivery appointment [4].

The effectiveness of this technique was reported in several studies, evaluating bond strength and marginal adaptation [5-8]. Still, little is known about the behavior of this technique in nanoleakage tests. The term "nanoleakage" has been used to describe microporous zones as the pathway for degradation of a bonded interface, either in completely cured adhesive resin, within the hybrid layer, and/or demineralized dentin, that allow tracer penetration to occur in the absence of interfacial gaps [9].

Furthermore, most studies were performed on flat surfaces, not considering factors like cavity configuration, thermal variations and masticatory forces, which can influence in the long-term durability of the restorations $[10,11]$. Due to the constant and fast evolution of the dental materials, does not exist a protocol about the proper combination between adhesive system and a liner, to be used with this technique [12].

Therefore, the aim of this study was to evaluate the nanoleakage patterns in indirect composite restorations bonding to dentin using different combinations of resin-coating technique, after thermal and load cycling.

\section{Methods}

Design of the study

Twenty five extracted third molars were used in the study; two box-like Class II cavities were prepared in each tooth (mesial and distal surface). The 50 cavities were distributed in 5 groups according to the Resin Coating (RC) materials combinations: G1: Etch-rinse 2steps/Hydrophobic monomer [Single Bond 2/Bond of Scotch Bond Multipurpose (SB2/ B)]; G2: Etch-rinse 2steps/Flow composite-resin [SB2/Filtek Flow (SB2/FL)], G3: Self-etch 1step [Clearfil S3 (CS3)], G4: Self-etch1step/Flowable composite resin liner [CS3/ Protect Liner (CS3/PL)], G5: Self-etch 2step/ Flowable composite-resin liner [Clearfil SE Bond/PL $(\mathrm{CSEB} / \mathrm{PL})]$. The cavities were molded with a vinyl polysiloxane impression material and the molds were poured with stone plaster. The fillings were confectioned using the Sinfony composite system ( $3 \mathrm{M} / \mathrm{ESPE})$ and cemented with resin luting cement (Rely X ARC). After 24 hours, the teeth were submitted to thermocycling (2000 cycles, $5^{\circ}$ to $\left.55^{\circ} \mathrm{C}\right)$ and load cycling $(250,000$ cycles, $30 \mathrm{~N})$. Past 24 hours, the restored teeth were sectioned into serial slabs and immersed in 50\% ammoniacal silver nitrate for $24 \mathrm{~h}$, exposed to photo-developing solution for $8 \mathrm{~h}$, carbon coated and observed in SEM using backscattered electron mode.

\section{Sample preparation}

Twenty five extracted third molars were used in the study, under the Ethical approval was obtained by the local Research Ethics Committee. The periodontal ligament was simulated applying a layer of polyether (Impregum, 3 M ESPE AG, Seefeld, Germany) over the roots [1]. Than, the apical side of the teeth was embedded in epoxi resin leaving the crown and $2 \mathrm{~mm}$ of root exposed. The cavities preparations were performed in a machine in order to standardize the dimensions of the cavities. Two box-like Class II 
cavities were prepared using diamond burs (\#4137 KG Sorensen Barueri SP, Brazil) that had the following dimensions: $4 \mathrm{~mm}$ of bucco-lingual width and $3 \mathrm{~mm}$ of proximal-axial width. The gingival margin of the cavity was located $1 \mathrm{~mm}$ below the cement-enamel junction. The dimensions and characteristics of the cavities are detailed in Figures $1 \mathrm{~A}$ and $1 \mathrm{~B}$. The cavities were randomly distributed in 5 groups $(\mathrm{n}=10)$. The materials used in each group and composition are described in Table 1.

\section{Aplication techinique of the RCT}

The procedure for restoring the groups 1-5 was performed according to the technique RTC. All restorative procedures and application technique are shown in Table 2.

\section{Indirect restoration technique}

Impressions of the preparations were taken using putty and light (Aquasil, Dentsply De Trey, Konstanz, Germany). The PVC cylinder $(12.5 \mathrm{~mm})$ fixed to a metallic handle was used as an impression tray. After one hour, the casts were poured in stone (Durone IV, Dentsply, Petropolis, RJ, Brazil) and removed after 60 minutes. Indirect restorations, which were previously isolated with Isolacril (Asfer, São Paulo, SP, Brazil), were made on the stone with a composite Sinfony System (3 M ESPE AG, Seefeld, Germany) using the incremental technique, starting with the proximal box followed by the occlusal box. Each increment was light cured for 40 seconds using the XL 2500 curing unit (ESPE, Germany; Norristow, PA, USA).
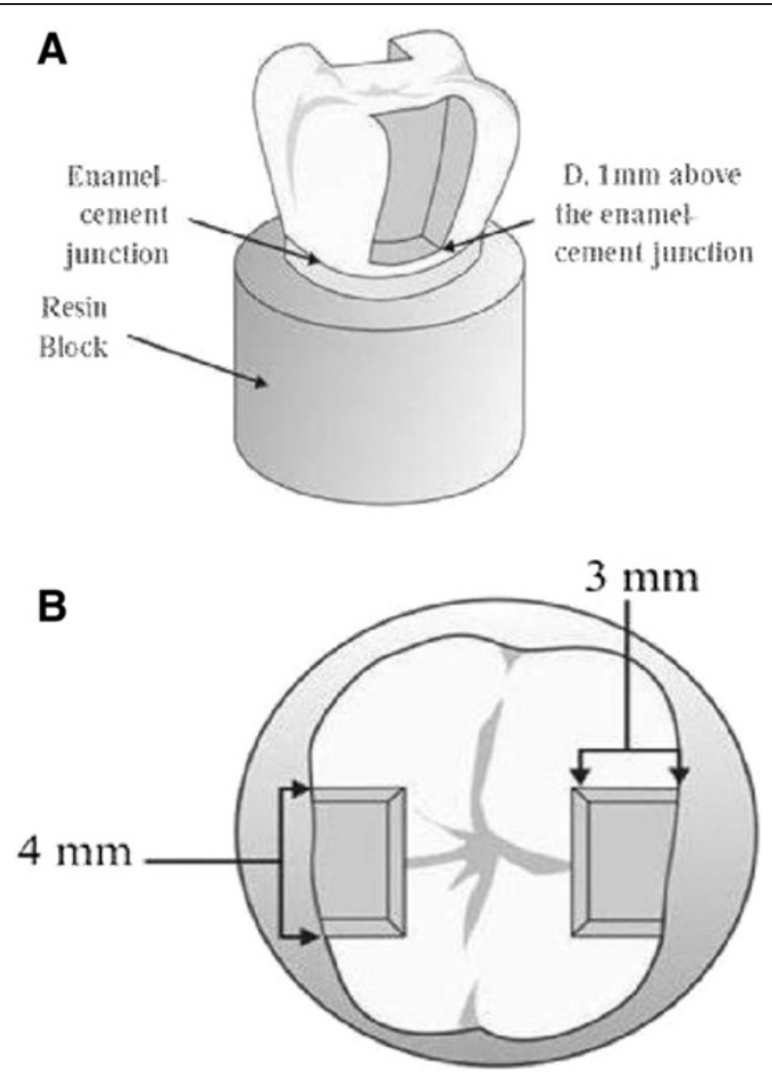

Figure 1 Characteristics (A) and measurements (B) of class II cavity. 
Table 1 Materials used in the study

\begin{tabular}{|c|c|c|}
\hline Materials & Composition & Manufacturer/batch \# \\
\hline $\begin{array}{l}\text { Single bond } \\
2 \text { (SB2) }\end{array}$ & $\begin{array}{l}\text { Water, ethanol, Bis-GMA, HEMA, UDMA, Bisphenol A glyceralote, } \\
\text { polyalquenoic acid copolymer, dimetacrylate, nanofiller }\end{array}$ & $\begin{array}{l}3 \text { M/ESPE. St. Paul, } \\
\text { MN, USA \#5EP }\end{array}$ \\
\hline $\begin{array}{l}\text { Scotch bond } \\
\text { multipurpose (B) }\end{array}$ & - Bond SBMP: Bis-GMA, HEMA, photoinitiator & $\begin{array}{l}3 \text { M/ESPE. St. Paul, } \\
\text { MN, USA \#5HP }\end{array}$ \\
\hline Filtek flow (FL) & Bis-GMA, TEGDMA, Zirconia, Sílica, camphorquinone, nanofilller & $\begin{array}{l}3 \text { M/ESPE. St. Paul, } \\
\text { MN, USA \#6031A2 }\end{array}$ \\
\hline Clearfil S3 (CS3) & $\begin{array}{l}\text { MDP, Bis-GMA, HEMA, hydrophobic dimetacrylate, photoinitiator, } \\
\text { ethanol. }\end{array}$ & $\begin{array}{l}\text { Kuraray Medical, Tokio, } \\
\text { Japan \# } 00001 \text { A }\end{array}$ \\
\hline Protect liner $(\mathrm{PL})$ & $\begin{array}{l}\text { Bis-GMA,TEGDMA, fluoride methil methacrylate, camphorquinone, } \\
\text { silanized colloidal silica. }\end{array}$ & $\begin{array}{l}\text { Kuraray Medical, Tokio, } \\
\text { Japan F \# } 0046\end{array}$ \\
\hline $\begin{array}{l}\text { Clearfil SE } \\
\text { bond (CSEB) }\end{array}$ & MDP, Bis-GMA, HEMA, hydrophobic dimetacrylate, photoinitiator. & $\begin{array}{l}\text { Kuraray Medical, Tokio, } \\
\text { Japan \# 00001A }\end{array}$ \\
\hline Rely X ARC & $\begin{array}{l}\text { BisGMA TEGDMA, Functionalized dimethacrylate polymer, } \\
\text { silane treated Zirconia and Silica, 2-benzotriazolyl-4-methylphenol, } \\
\text { 4-(dimethylamino)-benzeneethanol }\end{array}$ & $\begin{array}{l}3 \text { M/ESPE. St. Paul, } \\
\text { MN, USA \#5HP }\end{array}$ \\
\hline
\end{tabular}

Bis-GMA: bisphenol-A diglycidil ether dimethacrylate, HEMA: 2-hydroxyethyl metacrylate, MDP: 10 metacryloyloxydecyl dihidrogen phosphate, TEGDMA: triethylene glycol dimetacrylate.

\section{Cementation procedures}

The cavities were etched with 35\% phosphoric acid (3 M ESPE AG, Seefeld, Germany) for $15 \mathrm{~s}$, water rinsed and air blasted to remove the excess of water. Single Bond 2 (3 M ESPE, St. Paul, MN, USA) was applied by dual-application [13], each coat was gently air dried ( $5 \mathrm{~s})$, and then light-cured with a quartz-tungsten-halogen light-curing unit $\left(500 \mathrm{~mW} / \mathrm{cm}^{2}\right)(X L 2500,3 \mathrm{M}$ ESPE, St. Paul, MN, USA) for $10 \mathrm{~s}$. The internal surface of the restorations were sandblasted with $50 \mu \mathrm{m} \mathrm{Al} \mathrm{O}_{3}$ powder at 2-bar pressure and treated with 35\% phosphoric acid (3 M ESPE AG, Seefeld, Germany) for $1 \mathrm{~min}$. Following, a silane drop (Ceramic Primer, 3 M ESPE, St. Paul, MN, USA) was applied, let to dry for $30 \mathrm{~s}$ and air blasted. A layer of Single Bond 2 was applied and light-cured for $10 \mathrm{~s}$. The dual cured resin luting agent Rely X ARC (3 M/ESPE, St. Paul, MN, USA) was, then, applied in the internal surface of the restoration and the restoration was inserted in the cavity preparation under digital pressure. The excess of luting cement was removed and light-cured for $40 \mathrm{~s}$ through each surface of the tooth. Finishing was made with fine and extra-fine grit diamond burs (2135 F and 2135FF, KG Sorensen, Barueri, SP, Brazil) and polished with a series of sandpaper disks (Sof-Lex, 3 M/ESPE, St. Paul, MN, USA). The samples were stored at $37^{\circ} \mathrm{C}$ for 24 hours.

Table 2 Groups, materials and application technique used in this study

\begin{tabular}{lll}
\hline Groups & Materials & Application \\
\hline SB2/B (Etch-rise 2step/hydrophobic monomer) & Single bond 2 bond SBMP & a, b, c, d, e, d, e, k j, k \\
SB2/FL (Etch-rinse 2step/flow composite resin) & Single bond 2 filtek flow & a, b, c, d, e, d, e, k i, k (20 s) \\
CS3 (Self-etch 1step) & Clearfil S3 & h, e, k \\
$\begin{array}{l}\text { CS3/PL (Self-etch 1step/flowable composite } \\
\text { resin liner) }\end{array}$ & Clearfil S3 protect liner & h, e, k k (20 s) \\
$\begin{array}{ll}\text { CSEB/PL (Self-etch 2step/flowable composite } \\
\text { resin liner) }\end{array}$ & Clearfil SE bond protect liner & f, e, g, e, k k (20 s) \\
\hline
\end{tabular}

Application technique: a: acid technique (15 s); b: rinse surface (15 s); c: dry with cotton-pellet; d: apply one layer total etch one step adhesive; e: gently air dry $(5 \mathrm{~s})$; f: apply primer two step self-etch adhesive (20 s); g: apply bond two step self-etch adhesive; h: apply one layer self-etch one step adhesive (20 s); i: apply one layer resin flow; j: apply bond three step etch and rinse adhesive, $\mathrm{K}$ : light cure (10 s). 


\section{Conditioning the specimens}

The specimens were subjected to 2,000 thermal cycles from $5^{\circ}$ to $55^{\circ} \mathrm{C}$, with bath time of $60 \mathrm{~s}$, using a thermo-cycling machine (MSCM, Marcelo Nucci ME Instrument, São Carlos, SP, Brazil). Following, the specimens were submitted to the mechanical load cycling, using an equipment (MSCT-3, Marcelo Nucci ME Instrument, São Carlos SP, Brazil) that consists of five stainless steel pistons with cylindrical tips of $8 \mathrm{~mm}$ of diameter and rounded extremities, these tips where kept in contact with the occlusal surface of the restorations. The equipment applies an intermittent axial force of $50 \mathrm{~N}$ at a frequency of $2 \mathrm{~Hz}$, totalizing 250,000 cycles, under water at $37^{\circ} \mathrm{C}[8]$.

\section{Nanoleakage evaluation}

After thermal and load cycling, the teeth were sectioned into $1 \mathrm{~mm}$ thick slabs using a low-speed diamond saw (Isomet Buehler Ltd. IL, USA) and then stored in distilled water at $37^{\circ} \mathrm{C}$ for $24 \mathrm{~h}$. A total of 20 slabs were obtained for each group. Following, all the slabs were coated with two layers of acid resistant varnish (Revlon nail enamel, SP, Brasil), except for a $1 \mathrm{~mm}$ width around the adhesive layer and immersed in 50\% ammoniacal silver nitrate $(\mathrm{pH}=9.5)$ solution for $24 \mathrm{~h}$ [14]. Specimens were then thoroughly rinsed in distilled water and immersed in a photo-developer solution (Kodak Rochester, NY, USA) for 8 hours under a fluorescent light. After that, embedded in epoxy resin (Buehler Ltd., Lake Bluff, IL, USA) and polished with silicon carbide papers of ascending grits \# 600, 1200, 2000 and diamond pastes 1, 0.3, $0.05 \mu \mathrm{m}$ (Arotec Ind. e Co. Granja Viana, SP, Brasil). Specimens were then ultrasonically cleaned after the use of each polishing paste. All the specimens were dehydrated in increasing alcohol concentration $(25,50,75,100 \%)$ and immersed in HMDS (Hexamethyldisilazane) for $10 \mathrm{~min}$ [15]. Then mounted on aluminum stubs, carbon coated (MED 010, Balzers Union, Balzers, Liechstenstein) and examined in a Scanning Electron Microscopy (JEOL-5600 LV, Japan), using backscattered electron mode.

\section{Results and discussion}

All specimens in the five groups showed nanoleakage. Representative SEM backscattered electron images are represented in Figures 2, 3, 4, 5 and 6. In Figures 2A and 2B, $\mathrm{SB} 2 / \mathrm{B}$ group showed the silver presence in the entire thickness of the hybrid layer and adhesive layer and in some parts of the liner. In Figures $3 \mathrm{~A}$ and $3 \mathrm{~B}$, the nanoleakage pattern for the SB2/FL group showed the silver presence in the entire hybrid layer, differing from SB2/B by less silver presence in the adhesive layer and none in the liner. For the CS3 group, represented by Figures $4 \mathrm{~A}$ and $4 \mathrm{~B}$, a nanoleakage pattern within the adhesive layer similar to "water trees" can be observed. In Figures 5A and $5 \mathrm{~B}$, the CS3/PL group showed a nanoleakage pattern within the adhesive layer similar to "water trees" and in some parts silver deposits in the liner layer. The CSEB/PL group presented by Figures $6 \mathrm{~A}$ and $6 \mathrm{~B}$, it can be observed the silver presence only in the hybrid layer.

The constant advances of adhesive materials jeoperdize the execution of valid longterm clinical studies, demanding evidence from in vitro studies that simulate the oral conditions [16]. The use of thermal and load cycling simulate stresses undertaken by dental restorations and helps to better understand the dental materials $[17,18]$. 

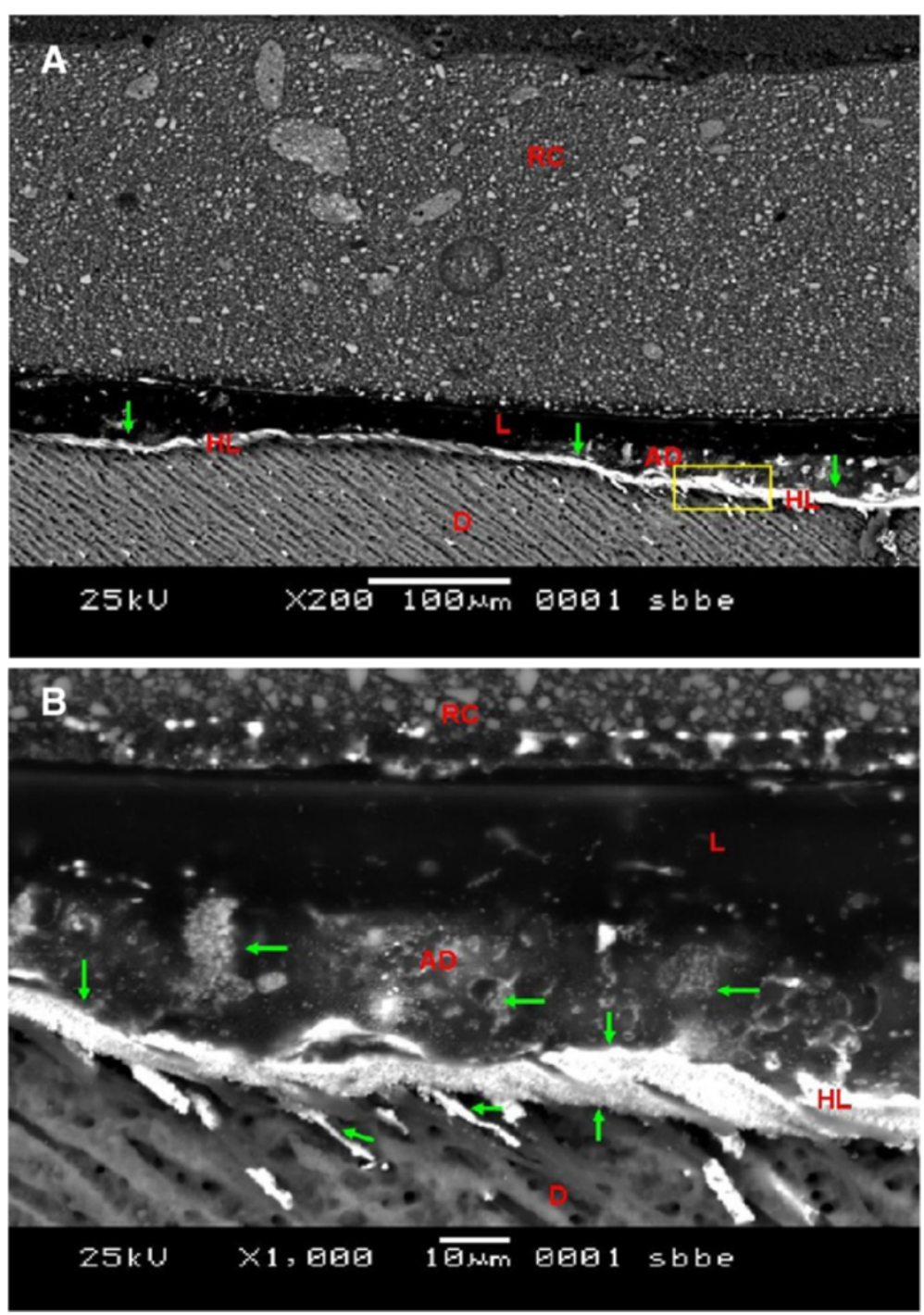

Figure 2 Backscattered images of the group SB2/B. In (A) (200x) silver deposition (green narrows) was observed in the entire Hybrid Layer (HL) and adhesive layer. In (B) (1000X) nanoleakage in the entire HL and adhesive layer (AD) and in parts of the Liner. (RC: Resin Cement, D: Dentin, L: Liner-hydrofobic monomer).

In theory, the fatigue resulting from the masticatory forces generates stresses in the interface tooth/restoration, increasing the damages in this area [19-21], as well as, the temperature changes induce interfacial stresses due to differences of contraction and expansion in the adhesive interface. These tensions may cause microcracks, which propagates through the interface [22]. Therefore, the thermo-mechanical simulation might provide results closer to the clinical situation.

Several studies that evaluate nanoleakage was performed on a flat surface [23,24]. In the present study, box-type class II cavities were confectioned, so that the influence of the $\mathrm{C}$-factor was not excluded once the cavity configuration simulates the clinical oral situation.

In etched groups (SB2/B and $\mathrm{SB} / \mathrm{FL})$ the silver penetration in the entire thickness of the hybrid layer is not just the result of adsorption and deposition of silver into the porosities; silver particles can also adheres with collagen fibers indicating that the 

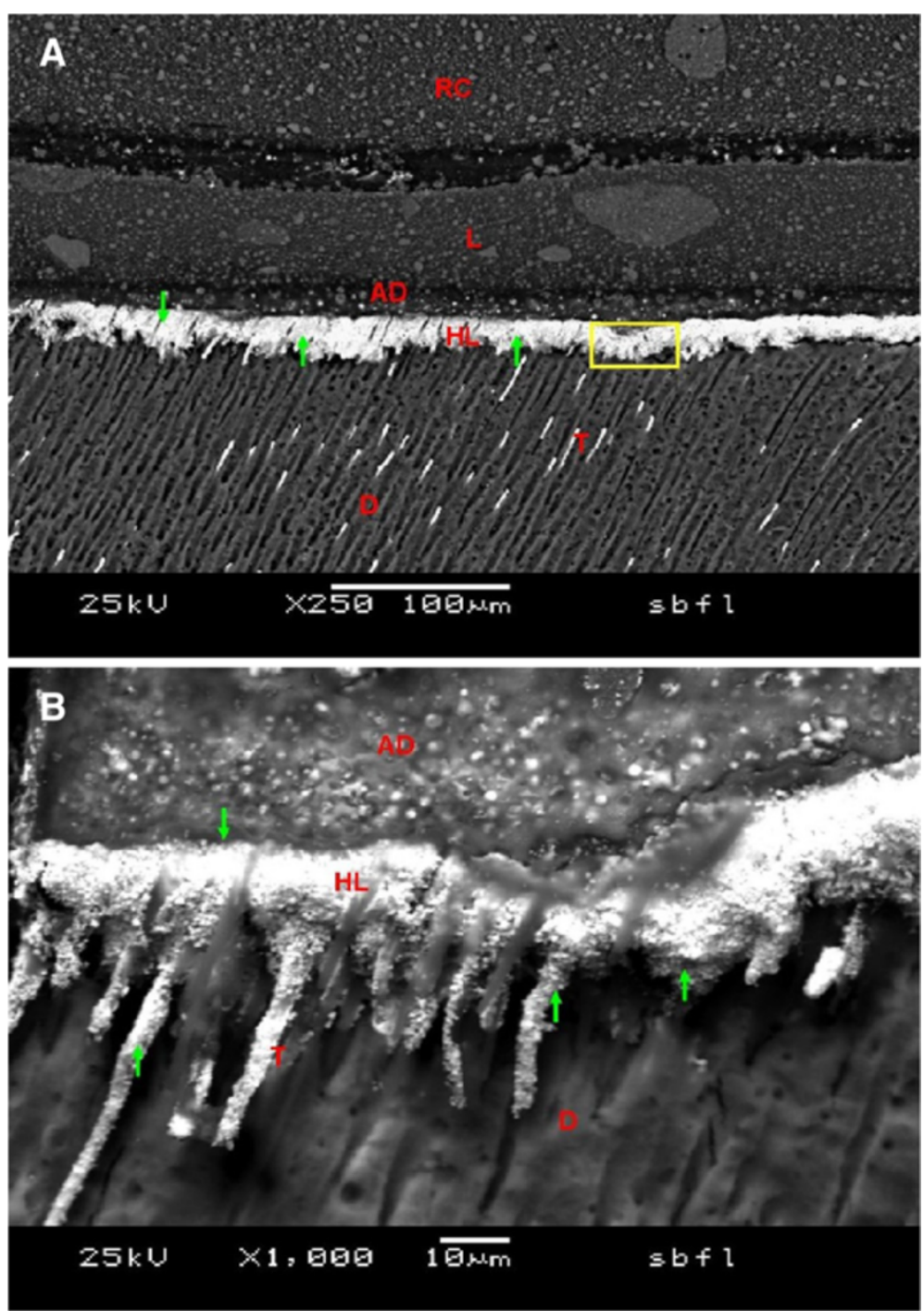

Figure 3 Backscattered images of the SB2/FL group. In (A) (250X) silver deposition (green narrows) was observed in the entire thickness of the Hybrid Layer $(\mathrm{HL})$ and in parts of the adhesive layer. In (B) (1000X) nanoleakage in the entire HL and in some parts of the adhesive layer (AD). (RC: Resin Cement, D: Dentin, L: Liner-Low viscosity resin, T: Tag resins).

adhesive system did not completely permeate the demineralized dentin, leaving a hybrid layer with large amounts of porosity which may subsequently allow dentinal or oral fluid to diffuse along the interface and, subsequently, hydrolyzes the adhesive resin and degreads the collagen fibrils [9,25]. However, in SB2/B group, more nanoleakage in the hybrid layer was observed, which included the entire thickness of the adhesive layer, different to the SB/FL group, where the nanoleakage was limited to the hybrid layer. This can be explained due to the mechanical properties of the material since $\mathrm{SB} / \mathrm{FL}$ used a low viscosity resin as a liner. This material absorbs the stress caused by the thermo-mechanical treatment better than the hydrophobicmonomer $[25,26]$.

In "all in one" self-etch groups (CS3 and CS3/PL) a different nanoleakage pattern could be observed. Presumably silver tracer should be absent when no discrepancy exits between the depth of demineralization and the extent of adhesive infiltration. However, 

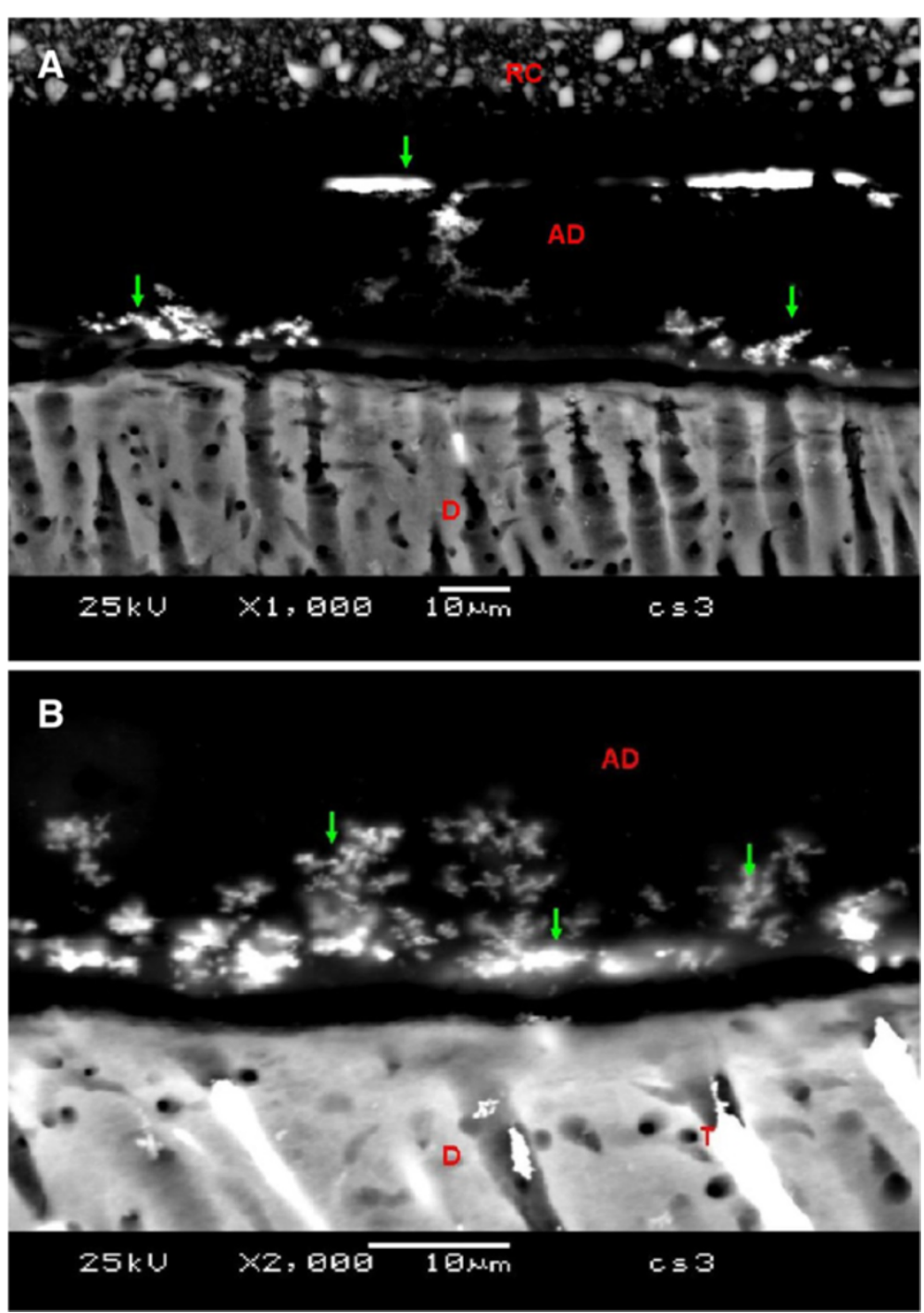

Figure 4 Backscattered images of the CS3 group. In (A) (1000x) nanoleakage (green narrows) was observed in the Adhesive Layer "water tree". (B) (2000x). (RC: Resin Cement, D: Dentin, T: Tag resins).

silver deposits similar to water tree were observed in both groups and these water channels extend through the adhesive layer, which provides the most direct way for water movement across the polymerized layers [27]. These regions represent areas of sub-optimal conversion within the polymer matrix due to the incompletely removal of solvent $[9,28]$. On the other hand, since Clearfil S3 adhesive contains 2-hydroxyethyl metacrylate - HEMA (hydrophilic monomer) and water, it is important to perform strong air drying to evaporate water and solvents. This procedure results in a viscous resin material with entrapped air bubbles remaining on the dentin surface and reduces the thickness of the layer, turning it more susceptible to the polymerization inhibition by oxygen [29].

Additionally, nanoleakage within the liner layer was observed for the CS3/PL group. This can be explained by the composition of this material which presents a lower amount of filler (42\%wt) compared to other low viscosity resins (Filtek Flow Z-350: $65 \% \mathrm{wt}$ ). Considering that the filler influences in the mechanical resistance of the 

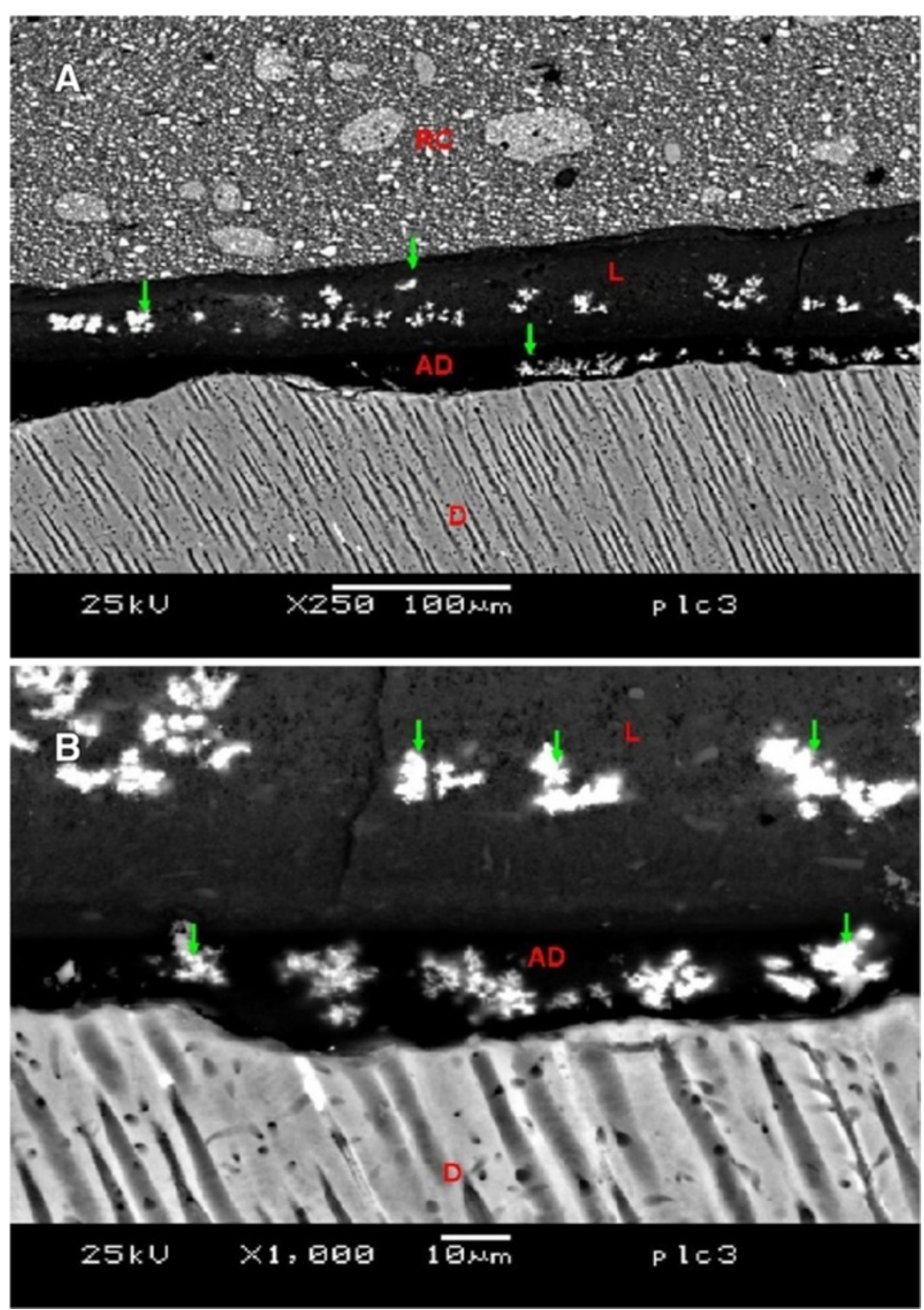

Figure 5 Backscattered images of the CS3/PL group. In (A) (250X) water tree (green narrows) was observed in the Adhesive Layer (AD) and silver depositions in the Liner layer (L). In (B) (2000X) nanoleakage in the adhesive layer and in the liner similar to water tree (AD). (RC: Resin Cement, D: Dentin, L: Liner-Low viscosity resin).

material and this, associated to the poorly polymerization of the adhesive, suggests that the liner layer is that support all the stress produced by the thermal-load cycling.

The CSEB/PL group, revealed less nanoleakage than the others groups and such infiltration was limited to the hybrid layer. This could be explained by the composition of the hybrid layer (resin and collagen fibrils). This adhesive is more stable compared to Clearfil S3 since this system presents primer and bond in separated bottles, while "all in one" adhesives present all the components (primer, bond and solvent) in one bottle, therefore less stable and prompt to phase separation [30]. On the other hand, it has been observed that the combination of the self-etch adhesive 2 steps (Clearfil SE Bond) with a low viscosity resin (Protect Liner F) can withstand the thermal-load cycling better, compared to the others groups tested and these results are according to others studies [11]. 

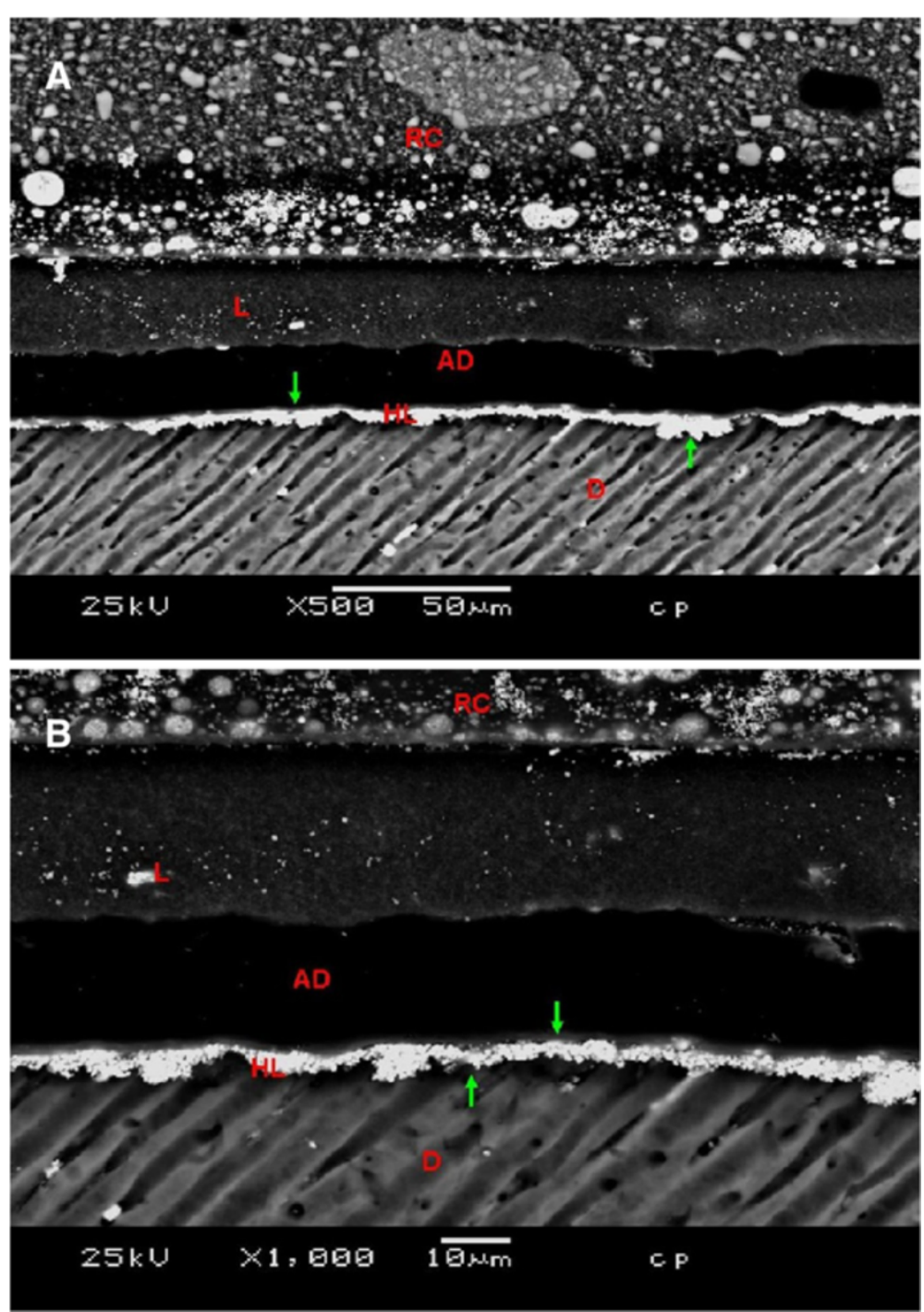

Figure 6 Backscattered images of the CSEB/PL group. In (A) (500x) silver deposition (green narrows) was observed in the entire thickness of the hybrid layer. In (B) (1000X) some silver depositions observed in the liner layer. (RC: Resin Cement, D: Dentin, L: Liner-Low viscosity resin).

\section{Conclusions}

Taking into consideration the above, we can conclude that: 1) All the indirect restorations showed nanoleakage, independent of the material combination used for the resin coating; and 2) The combination of self-etch 2 steps/low viscosity resin presented a superior behavior showing lower nanoleakage compared to the other groups.

\section{Abbreviations}

RCT: Resin coating technique; RC: Resin coating; SB2: Single bond 2; B: Bond of scotch bond multipurpose; FL: Filtek flow; CS3: Clearfil S3; PL: Protect liner; CSEB: Clearfil SE bond/PL; HEMA: 2-hydroxyethyl metacrylate.

\section{Competing interests}

There are no financial or non-financial competing interests to declare.

Authors' contributions

ABP and FSN carried out the sample preparation, the indirect restorations manufacture and cementations. ADCM carried out the conditioning the specimens and the nanoleakage evaluation. RMPR and LCS performed the analysis of the 
nanoleakage and statistical analysis. MAC conceived of the study and participated in the design of the study. All authors read and approved the final manuscript.

\section{Acknowledgements}

This study was supported by FAPESP. The authors are indebted to Mr. Adriano Martins and Dr. Luciana Salvio for technical microscopy support.

\section{Author details}

1'Department of Operative Dentistry, School of Dentistry - Peruvian University of Applied Sciences, Lima, Peru.

${ }^{2}$ Department of Restorative Dentistry, Dental Materials Division, Piracicaba Dental School, State University of Campinas-UNICAMP, Piracicaba, SP, Brazil. ${ }^{3}$ Department of Restorative Dentistry, Dental Materials Division, Piracicaba Dental School, State University of Campinas-UNICAMP, Piracicaba, SP, Brazil and Department of Restorative Dentistry, State University of Western Paraná-UNIOESTE, Cascavel, PR, Brazil. " ${ }^{4}$ Department of Pediatric Dentistry, Piracicaba Dental School, State University of Campinas - UNICAMP, Piracicaba, SP, Brazil.

\section{Received: 3 September 2013 Accepted: 5 November 2013}

\section{Published: 2 June 2014}

\section{References}

1. Belli S, Inokoshi S, Ozer F, Pereira PM, Ogata N, Tagami J (2001) The effect of additional enamel etching and a flowable composite to the interfacial integrity of Class II adhesive composite restorations. Oper Dent 26:70-75

2. Satoh M (1994) How to use liner bond system as a dentin and pulp protector in indirect restorations. Jap J Adhes Dent 12:41-47

3. Nikaido T, Yoda A, Foxton R, Tagami I (2003) A resin coating technique. Int Chin J Dent 3:62-68

4. Swift EJ, Jr (2009) Critical appraisal: immediate dentin sealing for indirect bonded restorations. J Esthet Restor Dent 21(1):62-67

5. Behr M, Rosentrit M, Leybrock A, Scheneider Feyrer S, Handel G (1999) In-vitro study of fracture strength and marginal adaptation of fibre-reinforced adhesive fixed partial inlaydentures. JDent 27:163-168

6. Nikaido T, Kunzelmann KH, Chen H, Ogata M, Harada N, Yamaguchi S, et al. (2002) Evaluation of thermal cycling and mechanical loading on bond strength of a self-etching primer system to dentin. Dent Mater 18:269-275

7. Shirai K, Munck D, Yoshida Y, Inoue S, Lambrechts P, Suzuki K, et al. (2005) Effect of cavity configuration and aging on the bonding effectiveness of six adhesives to dentin. Dent Mater 21:110-124

8. Feitosa VP, Medina AD, Puppin-Rontani RM, Correr-Sobrinho L, Sinhoreti MA (2010) Effect of resin coat technique on bond strength of indirect restorations after thermal and load cycling. Bull Tokyo Dent Coll 51(3):111-118

9. Sano H, Takatsu T, Ciucchi B, Horner JA, Matthews WG, Pashley DH (1995) Nanoleakage: leakage within the hybrid layer. Oper Dent 20:18-25

10. Di Francescantonio M, Aguiar TR, Oliveira MT, Giannini M (2011) Influence of viscosity and polymerization mode on bond strength of dual-cure resin luting agent to dentin. Braz J Oral Sci 11(1):76-80

11. Mousavinasab SM, Farhadi A, Shabanian M (2009) Effect of storage time, thermocycling and resin coating on durability of dentin bonding systems. Dent Res J (Isfahan) Spring 6(1):29-37

12. Nikaido T, Cho E, Nakajima M, Tashiro H, Toba S, Burrow M, Tagami J (2003) Tensile bond strengths of resin cements to bovine dentine using resin coating. J Dent 16:41-46

13. Takahashi R, Nikaido T, Ariyoshi M, Kitayama S, Sadr A, Foxton RM, Tagami J (2010) Thin resin coating by dualapplication of all-in-one adhesives improves dentin bond strength of resin cements for indirect restorations. Dent Mater J Oct 29(5):615-622

14. Tay FR, Pashley DH, Yoshiyama M (2002) Two modes of nanoleakage expression in single-step adhesives. J Dent Res 81:472-476

15. Perdigao J (1995) Field emission SEM comparison of four post fixation drying techniques for human dentin. J Biomed Mater Res 29:1111-1120

16. Ferracane JL (2011) Resin composite-state of the art. Dent Mater 27(1):29-38

17. Frankenberger R, Pashley DH, Reich SM, Lohbauer U, Petschelt A, Tay FR (2005) Characterization of resin-dentine interfaces by compressive cyclic loading. Biomater 26:2043-2052

18. Kitayama S, Nasser NA, Pilecki P, Wilson RF, Nikaido T, Tagami J, Watson TF, Foxton RM (2011) Effect of resin coating and occlusal loading on microleakage of Class II computer-aided design/computer-aided manufacturing fabricated ceramic restorations: a confocal microscopic study. Acta Odontol Scand May 69(3):182-192

19. Heintze SD (2006) How to qualify and validate wear simulation devices and methods. Dent Mater 22:712-734

20. Jayasooriya PR, Pereira P, Nikaido T, Burrow MF, Tagami J (2003) The effect of resin coating on the interfacial adaptation of composite inlays. Oper Dent 28:28-35

21. Toledano M, Osorio R, Albaladejo A, Aguilera FS, Tay F, Ferrari M (2006) Effect of cycling loading on the microtensile bond strengths of total etch and self-etch adhesives. Oper Dent 31:25-32

22. Irie M, Suzuki K (2001) Current luting cements: marginal gap formation of composite inlay and their mechanical properties. Dent Mater 17:347-353

23. Hashimoto M, De Munck J, Ito S, Sano H, Kaga M, Oguchi H, Van Meerbeek B, Pashley DH (2004) In vitro effect of nanoleakage expression on resin-dentin bond strengths analyzed by microtensile bond test, SEM/EDX and TEM. Biomater 25:5565-5574

24. Shafiei F, Doozandeh M, Alavi AA (2011) Effect of resin coating and chlorhexidine on the microleakage of two resin cements after storage. J Prosthodont 20(2):106-112

25. Sano H, Shono T, Takatsu T, Hosoda H (1994) Microporous dentin zone beneath resin-impregnated layer. Oper Dent 19:59-64

26. Dietschi D, Bindi G, krejci I, Davidson C (2002) Marginal and internal adaptation of stratified compomer composite class II restorations. Oper Dent 27:500-509 
27. Tay FR, Pashley DH (2003) Water treeing - a potential mechanism for degradation of dentin adhesives system. Amer J Dent 16:6-12

28. Li H, Burrow MF, Tyas MJ (2000) Nanoleakage patterns of four dentin bonding systems. Dent Mater 16:48-56

29. Rueggeberg FA, Margeson DH (1990) The effect of oxygen inhibition on an unfilled/filled composite system. J Dent Res 69:1652-1658

30. Gaintantzopoulou M, Rahiotis EG (2008) Molecular characterization of one-step self-etching adhesives placed on dentin and inert substrate. J Adhes Dent 10:83-93

doi:10.1186/2196-4351-2-5

Cite this article as: Medina et al:: Nanoleakage in indirect composite restorations using different combinations of resin coating technique. Applied Adhesion Science 2014 2:5.

\section{Submit your manuscript to a SpringerOpen ${ }^{\circ}$ journal and benefit from:}

- Convenient online submission

- Rigorous peer review

- Immediate publication on acceptance

- Open access: articles freely available online

- High visibility within the field

- Retaining the copyright to your article

Submit your next manuscript at $>$ springeropen.com 